\title{
Experimental Evaluation of Dry Powder Inhalers During In- and Exhalation Using a Model of the Human Respiratory System (XPULM ${ }^{\mathrm{TM}}$ )
}

\author{
Richard Pasteka ${ }^{1,2, *}$, Joao Pedro Santos da Costa ${ }^{1}$, and Mathias Forjan ${ }^{1}$ \\ ${ }^{1}$ University of Applied Sciences Technikum Wien, Department Life Science Engineering, Vienna, 1200, Austria \\ ${ }^{2}$ Brno University of Technology, Department of Biomedical Engineering, Brno, 61600, Czech Republic \\ *richard.pasteka@technikum-wien.at
}

\begin{abstract}
Dry powder inhalers are used by a large number of patients worldwide to treat respiratory diseases. The objective of this work is to experimentally investigate changes in aerosol particle diameter and particle number concentration of pharmaceutical aerosols generated by five dry powder inhalers under realistic inhalation and exhalation conditions. The active respiratory system model (XPULM ${ }^{\mathrm{TM}}$ ) was used as a model of the human respiratory system and to simulate a patient undergoing inhalation therapy. A mechanical upper airway model was developed, manufactured and introduced as a part of the XPULM ${ }^{\mathrm{TM}}$ to represent the human upper respiratory tract with high fidelity. Integration of optical aerosol spectrometry technique into the setup allowed for evaluation of pharmaceutical aerosols. The results show that the upper airway model increases the resistance of the overall system and act as a filter for bigger particles $(>3 \mu \mathrm{m})$. Furthermore, there is a significant difference $(p<0.05)$ in mean particle diameter between inhaled and exhaled particles with the majority of the particles depositing in the lung. The minimum deposition is reached for particle size of $0.5 \mu \mathrm{m}$. The mean particle number concentrations exhaled are $2.94 \%$ (BreezHaler ${ }^{\circledR}$ ), 2.66\% (Diskus $\left.\AA^{\circledR}\right), 10.24 \%$ (Ellipta $\left.{ }^{\circledR}\right)$ 2.13\% (HandiHaler ${ }^{\circledR}$ ) and 6.22\% (Turbohaler $\left.{ }^{\circledR}\right)$. In conclusion, the xPULM ${ }^{\mathrm{TM}}$ active respiratory system model is a viable option for studying interactions of pharmaceutical aerosols and the respiratory tract in terms of applicable deposition mechanisms. The model can support the reduction of animal experimentation in aerosol research and provide an alternative to experiments with human subjects.
\end{abstract}

\section{Introduction}

According to the report of the Forum of International Respiratory Societies from $2017^{1}$ approximately 65 million people suffer from mild to severe COPD (chronic obstructive pulmonary disease) worldwide an additional 334 million people suffer from asthma. Together with acute lower respiratory tract infections, these diseases are among the most prevalent severe illnesses and causes of death. ${ }^{1}$ Based on Eurostat statistics ${ }^{2}$ in 2016, diseases of the respiratory system account for approximately 7,5\% of all deaths in the former EU-27. Inhalation drug therapy plays a significant role in managing cases of asthma and COPD.

Serino et al. define in their work ${ }^{3}$ four main types of inhalation therapeutic devices. These include nebulisers, pressurisedmetered dose inhalers (pMDI), soft mist inhalers (SMI) and dry powder inhalers (DPI). In contrast to pMDIs, dry powder inhalers work with larger lactose particles carrying the active substance and are environmentally preferable ${ }^{4}$. Additionally, they do not require a synchronised activity between activation and inhalation. Nevertheless, DPIs require a minimum peak flow during inhalation, created by the patient, to detach and propel the aerosol in direction of the lung regions. The work of Rau et al. ${ }^{5}$ concludes, that the lack of necessary synchronised actions during activation of the DPI is reducing a potential source of misuse on the one hand but does not cover for the problems caused by different activation mechanisms on the other hand. This work also establishes that the optimum flow profile is different for the currently available dry powder inhalers and may lead to a suboptimal delivered dose for the patients. ${ }^{5}$ The publication of Geller et al. ${ }^{6}$ concords with the previous statement and concludes that most recent DPIs only deliver a low dose of medication. Geller et al. ${ }^{6}$ also state that the users have to be able to create a minimum inspiratory flow and have to have the cognitive ability to use the DPI. This is accompanied by the need for an adequate lung volume of the user, and therefore usually rules out smaller children. Geller et al. state that the DPIs are usually not recommended for a patient with an age lower than 5 years $^{6}$. To assume a single peak inspiratory flow rate (PIFR) value as the main criterion for determining the capability of the patient to use an inhaler efficiently is a growing misconception ${ }^{7}$. Considering only the PIFR may be an insufficient criterion as the DPIs vary in their design and inner resistance. Several available studies evaluating dry powder inhalers focus mainly on inspiratory flow rate ${ }^{8-12}$. More suitable criteria seem to be to ensure a sufficient pressure drop across the device during inhalation. A pressure drop value of $\geq 1 \mathrm{kPa}$ with any DPI seems to be sufficient for the patient to receive an adequate lung dose of the pharmaceutical ${ }^{7}$. Focusing on the pressure drop 
across the device could help reduce insufficient or excessive peak inspiratory flow rate. Both have been shown to negatively impact pulmonary drug delivery ${ }^{8,13}$ Therefore, the pressure drop over the DPI has been taken as the main evaluation criterion for successful inhalation processes for this work.

In vitro pharmaceutical aerosol test systems often include either sample collection tubes, the Andersen non-viable impactor, or the Next Generation Impactor ${ }^{14-16}$. The results using such a system provide insights about the properties of the inhaled aerosol and can be compared with radio-nuclide imaging studies ${ }^{17}$. Additionally, the results obtained from in vitro measurements can help to validate in-silico dosimetry models ${ }^{18-20}$. Cascade impactors consist of stages, each containing impaction plates which represent obstacles for an incoming airstream ${ }^{21}$. The plate creates an abrupt bend in the airstream and causes particles whose inertia exceeds a cut off size, to deposit there ${ }^{22}$. Evaluation of the aerosol during exhalation is problematic, due to the operation principle of impactors. The aerosol particles deposit on impaction plates and therefore cannot be present in the airstream of simulated exhalation.

Pulmonary drug delivery needs to consider the primary mechanisms of aerosol deposition. Darquenne defines the primary mechanisms as the following: inertial impaction, gravitational sedimentation, Brownian diffusion, turbulent deposition, electrostatic precipitation, and interception. ${ }^{23}$ Tsuda et al. state $^{24}$ that how aerosol particles are affected by deposition mechanisms depends on the particle characteristics such as particle size, overall size distribution, shape, composition, surface characteristics and charge. Moreover, the processes resulting from molecular transfer between particles and their respective surrounding gas are nucleation, condensation, evaporation and hygroscopicity. The coagulation is caused by particle collisions which result in the formation of larger particles. In the human respiratory tract, the regional particle deposition is affected by different mechanisms and particle characteristics. Spherical particles are assumed to describe particle deposition in the upper respiratory tract, conducting airways and pulmonary acinus. The deposition mechanism occurring mainly in the upper airways is the inertial impaction affecting mostly large particles $(>2-5 \mu \mathrm{m})$ with a strong dependency on the airflow rate. The deposition in this region of the respiratory tract results from direction changes of flow when the particles deviate from the streamline and collide with the airway walls. The probability of such deviation can be described by the Stoke's number where particle diameter, carrier gas viscosity and airway diameter are used to calculate the probability of deposition. ${ }^{25}$ In the respiratory tract, gravitational sedimentation of particles in the size range of $(>1-8 \mu \mathrm{m})$, refers to the settling of particles under the influence of gravity. Brownian diffusion results from random motion and the collision of the particles with the carrier gas molecules. The effect of mutual repulsion due to electric charges concerning the inhaled particles is defined as electrostatic precipitation. The described mechanisms arise mostly in the upper and conducting airway region of the respiratory tract, whereas diffusion and electrostatic precipitation is also taking place in the acinus region of the pulmonary system for particles $<3 \mu \mathrm{m}$. $^{23}$

The objective of this work is to experimentally investigate changes in aerosol particle diameter and particle number concentration of pharmaceutical aerosols under realistic inhalation and exhalation conditions, resulting in a calculated total lung deposition. The active respiratory system model (xPULM) used in this work includes two core elements; a CT-derived upper airway model, and a primed porcine lung serving as human lung equivalent. In contrast to widely spread measurement setups, this work integrates an optical aerosol spectrometer for inhalation and exhalation measurements. This setup is used to represent a patient undergoing inhalation therapy. To cover a wide spectrum of devices used in clinical practice, five commonly used dry powder inhalers (DPI) are investigated. A focus was put on reaching a pressure drop of $\left(\mathrm{P}_{\mathrm{DROP}}=4 \mathrm{kP}\right)$ for all inhalers. The work aims to provide an alternative respiratory model suitable to reduce animal experimentation in aerosol research. Furthermore, the work aspires to mitigate the shortage of experimental data, viable to substitute demanding and constrictive experiments with human subjects. Moreover, the experimental setup including the XPULM ${ }^{\mathrm{TM}}$ model, can be seen as a basis for an alternative to animal testing, as the porcine lung, included in this trial, has been salvaged from an abattoir.

\section{Materials and Methods}

\section{The Measurement Setup and Procedure}

The following two measurement trials were conducted during this study: A) Characterisation measurements and B) Respiration measurements using the setup depicted in Figure 1. As a first step, Characterisation measurements were performed using a 90-degree bend as a connection to the respiratory model xPULM ${ }^{\mathrm{TM}}$. The aerosol sampling point was introduced in line with the inhalatory airstream to ensure isoaxial aerosol sampling. The active model of the human respiratory system, $\mathrm{xPULM} \mathrm{M}^{\mathrm{TM}}$, was used with polymer breathing bags, to simulate the inhalation effort of a patient, without introducing a complex inner geometry influencing the aerosol transport behaviour. In the second step, Respiration measurements (see Figure 1) were conducted to investigate changes in aerosol particle diameter and particle number concentration during inhalation and exhalation. For this purpose, a primed porcine lung was used as a lung equivalent. 


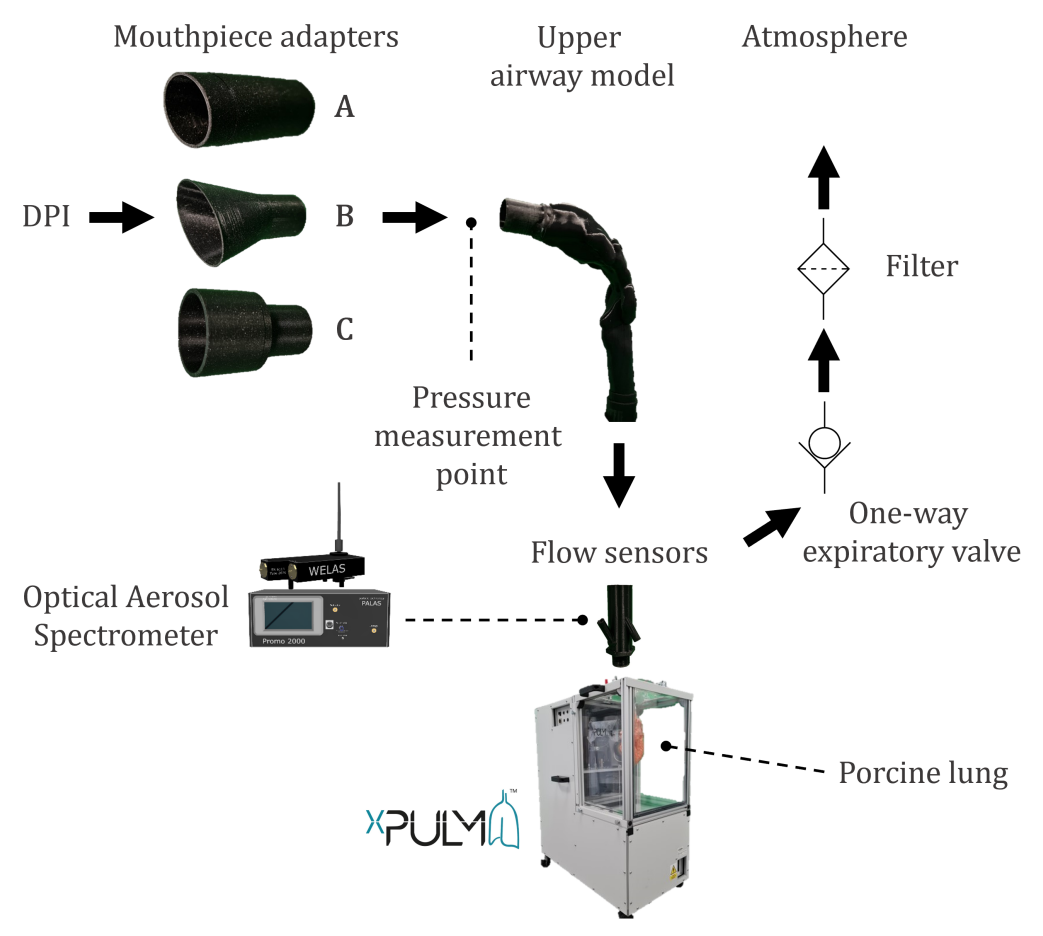

Figure 1. The measurement setup for Respiration measurements consisting of mouthpiece adapters for A) BreezHaler® B) Diskus ${ }^{\circledR}$, Ellipta ${ }^{\circledR}$, HandiHaler ${ }^{\circledR}$ C) Turbohaler ${ }^{\circledR}$, the upper airway model derived from CT examinations, optical aerosol spectrometer used to characterise the aerosol particles and the active model of the human respiratory system XPULM ${ }^{\mathrm{TM}}$ with porcine lung.

The measurement procedure of the Respiration measurements consists of three phases (i) inhalation, (ii) breath-hold, (iii) exhalation. Inhalation was simulated with a maximal effort until the pressure drop, measured with FlowAnalyser PF-300 (IMT Analytics, Switzerland), across the DPI reached $\mathrm{P}_{\mathrm{DROP}}=4 \mathrm{kP}$. Inhaler-specific inhalation profiles were recorded using mass flow sensors (Honeywell, USA).

Following the inhalation manoeuvres a $5 \mathrm{~s}$ breath-hold period started before slow and steady exhalation at a flow of $30 \mathrm{~L} / \mathrm{min}$ took place for $6 \mathrm{~s}$. For each tested DPI, the measurements were repeated 12 times $(n=12)$. The in-/exhalation airstream was sampled with a constant flow rate of $5 \mathrm{~L} / \mathrm{min}$. Particle size distribution was measured using a Promo 2000 (PALAS, Germany) optical aerosol spectrometer connected to a white light aerosol sensor Welas (PALAS, Germany).

\section{Model of the Human Respiratory System}

The active model of the human respiratory system XPULM ${ }^{\mathrm{TM}}$ has been used in this study. The XPULM ${ }^{\mathrm{TM}}$ replicates human breathing efforts exerted during the use of DPI. Fundamental respiratory characteristics (e.g., flow, pressure, and volume) of a rapidly inhaling human are captured during the simulation with high fidelity. Properties of the human respiratory system such as airway resistance and lung compliance are represented using lung equivalents and airway models.

The displacement of gasses during spontaneous breathing occurs due to the pressure difference between the atmosphere and the human lung. This physiological process is recreated by the $\mathrm{xPULM}^{\mathrm{TM}}$. During the breathing simulation, pressure changes in the thoracic chamber are induced by the movement of the bellows system. The air follows the pressure gradient resulting in inhalation or exhalation based on its direction. The movement of the bellows system can be adjusted in the control software of the $\mathrm{xPULM}{ }^{\mathrm{TM}}$ with high precision. This allows for the simulation of different breathing scenarios. A detailed description of the xPULM ${ }^{\mathrm{TM}}$ components together with validation measurements are presented in previous work of Pasteka et al. ${ }^{26}$. 


\section{Representation of the Upper Respiratory Tract}

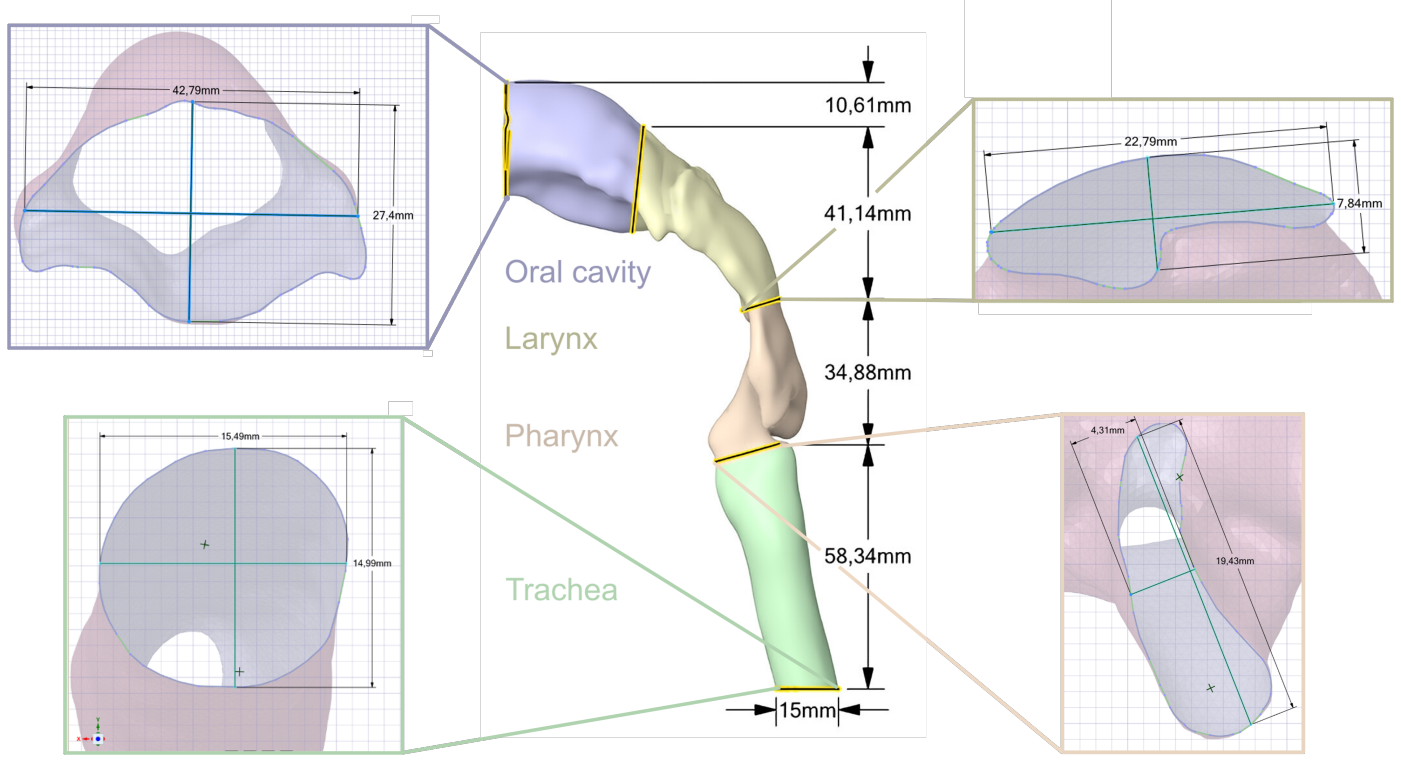

Figure 2. The resulting 3D model of an upper respiratory tract of a 28-years-old, healthy, non-smoking, male.

The upper airway model includes the oral cavity, oropharynx, larynx, and trachea up to the first bifurcation. Images acquired from computed tomography (CT) examination of a 28-years-old, healthy, non-smoking, male were used for the reconstruction. The resulting dataset contained 280 images with a slice thickness of $0.75 \mathrm{~mm}$ and was exported in a Digital Imaging and Communications in Medicine (DICOM) format for further processing. The upper respiratory tract was segmented using a combination of thresholding and region growing techniques. The outcomes of the semi-automatic segmentation were inspected on a slide-by-slide basis and the segmentation parameters were adapted to obtain only the upper airways. The resulting 3D model was exported as a Standard Triangle Language (STL) file and post-processed to be printable. The final 3D mechanical upper airway model was manufactured using rapid prototyping techniques. An emphasis was put on the positioning of the model. The dimensions for each section of the final model are summarised in Figure 2 and Table 1. Custom connectors were designed based on the geometry of each DPI to ensure an airtight connection between the inhaler and the upper airway model.

All rapidly produced components were manufactured from Polylactic acid (PLA) with a wall thickness of $2 \mathrm{~mm}$ and a layer height of $0.2 \mathrm{~mm}$.

Table 1. Summary of the upper airway model dimensions of a 28-years-old, healthy, non-smoking, male. The highlighted sections correspond to Figure 2. SA - surface area

\begin{tabular}{llllllll}
\hline \multicolumn{1}{|c}{ Section } & $\begin{array}{l}\text { Volume } \\
{\left[\mathrm{mm}^{3}\right]}\end{array}$ & $\begin{array}{l}\text { Lower SA } \\
{\left[\mathrm{mm}^{2}\right]}\end{array}$ & $\begin{array}{l}\text { Diameter Y } \\
{[\mathrm{mm}]}\end{array}$ & $\begin{array}{l}\text { Dimeter X } \\
{[\mathrm{mm}]}\end{array}$ & $\begin{array}{l}\text { Upper SA } \\
{\left[\mathrm{mm}^{2}\right]}\end{array}$ & $\begin{array}{l}\text { Diameter Y } \\
{[\mathrm{mm}]}\end{array}$ & $\begin{array}{l}\text { Diameter X } \\
{[\mathrm{mm}]}\end{array}$ \\
\hline Trachea (green) & 10657.02 & 188.39 & 15.49 & 14.99 & 86.60 & 18 & 4.93 \\
Pharynx (orange) & 7311.52 & 119.06 & 19.43 & 4.31 & 86.60 & 4.86 & 24.51 \\
Larynx (yellow) & 15902.39 & 119.11 & 7.84 & 22.79 & 777.57 & 24.93 & 44.34 \\
Oral cavity (blue) & 22265.60 & 777.60 & 7.84 & 22.79 & 529.90 & 7.84 & 22.79 \\
\hline
\end{tabular}

\section{Representation of the Lower Respiratory tract}

The lower respiratory tract consists of the bronchi, bronchioles, and alveoli, which together form the lung. During breathing simulations, these structures have been represented by primed porcine lung. The lung was salvaged from the slaughterhouse process and are therefore compliant with the $3 \mathrm{R}$ principles ${ }^{27}$ which represent responsible use of animal or animal organs during experiments. The Nasco-guard® (Nasco, Wisconsin, USA) preservation process keeps the porcine lung inflatable, elastic and covered with the parietal pleura. All these properties are necessary for physiologically and anatomically realistic simulations of human breathing. 


\section{Dry Powder Inhalers}

In total five DPIs were used in this study. Two of them were single-dose devices (BreezHaler® and HandiHaler ${ }^{\circledR}$ ) in which a capsule storing the dose is loaded into the device and punctured before use. The remaining three were multi-dose DPIs (Diskus ${ }^{\circledR}$, Ellipta ${ }^{\circledR}$, Turbuhaler ${ }^{\circledR}$ ) in which the dose is stored within the devices. Inlets of all DPIs were modified with custom rapidly manufactured adaptors to enable well-fitted connection to the oral cavity of the upper airway model.

Table 2. Summary of the relevant parameter values of used dry powder inhalers taken from the literature $\left[{ }^{7,28}\right]$.

\begin{tabular}{|c|c|c|c|c|c|}
\hline Device & Active substance & $\begin{array}{l}\text { Resistance } \\
{\left[\mathrm{kPa}^{1 / 2} / \mathrm{L} / \mathrm{min}\right]}\end{array}$ & $\begin{array}{l}\text { Metered Dose } \\
{[\mu \mathrm{g}]}\end{array}$ & $\begin{array}{l}\text { Lactose } \\
{[\mathrm{mg}]}\end{array}$ & Dose type \\
\hline Seebri® Breezhaler ${ }^{\circledR}$ & lycopyrronium & 0.0216 & 44 & 23.6 & e hi \\
\hline Seretide $₫$ Diskus $®$ & Salmeterol and fluticasone propionat & 0.0254 & $50 / 500$ & 12.5 & multi-dose, pre-dispensed \\
\hline Anoro® Ellipta ${ }^{\circledR}$ & Fluticasone furoate and vilanterol & 0.0286 & $55 / 22$ & 25 & multi-dose, pre-dispensed \\
\hline Spiriva ${ }^{\circledR}$ HandiHaler® & Tiotropium bromide & 0.0504 & 18 & 5.5 & single-dose, hard capsules \\
\hline Symbicort ${ }^{\circledR}$ Turbohaler ${ }^{\circledR}$ & Budesonide and formoterol & 0.0313 & $200 / 6$ & 0.73 & multi-dose, pre-dispensed \\
\hline
\end{tabular}

\section{Data Processing \& Statistics}

The measurements were conducted with 128 intervals per decade. The arithmetic centre of the intervals $\left(x_{i}\right)$ is then:

$$
x_{i}=x_{i, \text { lower }}+\frac{x_{i, \text { upper }}-x_{i, \text { lower }}}{2}=x_{i, \text { lower }}+\frac{\Delta x_{i}}{2}[\mu \mathrm{m}]
$$

For further calculations, the differential particle number distribution $q_{0}\left(x_{i}\right)$ is defined as:

$$
q_{0}\left(x_{i}\right)=\frac{1}{\sum n_{i}} \frac{n_{i}}{\Delta x_{i}}
$$

where $n_{i}$ is the measured particle number within the interval limits $x_{i, l o w e r}$ and $x_{i, u p p e r}$. Leading to the mean particle size $M_{1,0}$ calculation:

$$
M_{1,0}=\sum x_{i}^{1} q_{0}\left(x_{i}\right) \Delta x_{i}=\bar{x}[\mu m]
$$

Further information about the inhaled aerosol is obtained by calculating the particle number concentration:

$$
d C n=n_{i} \frac{1}{V_{m}}\left[P / \mathrm{cm}^{3}\right]
$$

where the measured volume $V_{m}$ is defined as:

$$
V_{m}=u I w t_{\text {measurement }}\left[\mu^{3}\right]
$$

where $u$ is particle velocity and $I w$ the cross-section of the optical sensor.

The measurement data is evaluated with non-parametric methods as the requirements for normal distribution and hence parametric test methods is not fulfilled. The data groups are pairwise compared by using the Kruskal-Wallis test by ranks (or one-way ANOVA on ranks) with a significance level of $\alpha=0.05, \mathrm{H}$ values and $\mathrm{p}$ values are calculated and compared to a critical $\chi^{2}=3.841$ for a degree of freedom $d f=1$. 


\section{Results and Discussion}

\subsection{Inhalatory flow rate and pressure drop measurements}
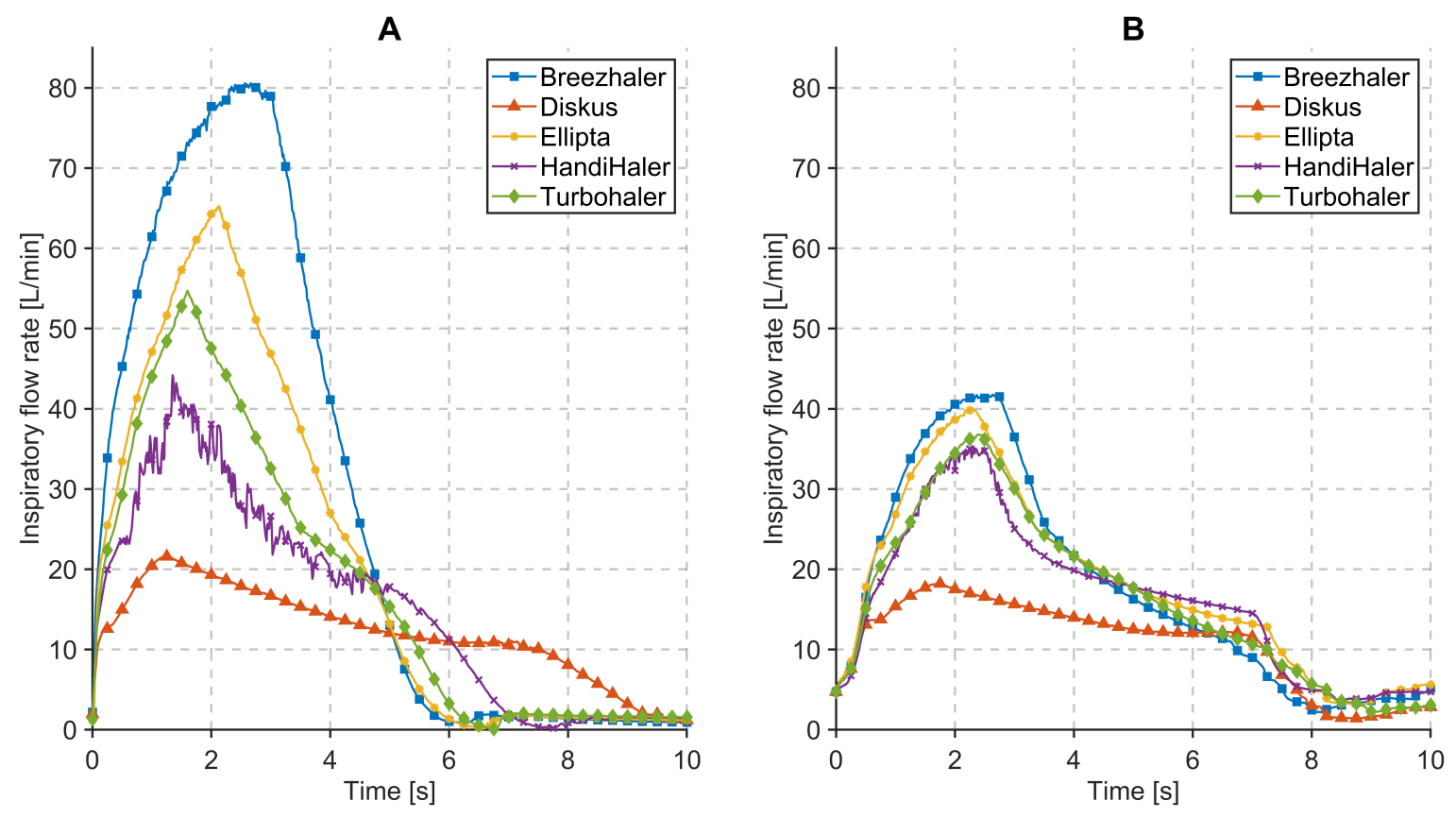

Figure 3. Flow profiles during A) Characterisation measurements B) Respiration measurements while inhaling through Breezhaler®, Diskus ${ }^{\circledR}$, Ellipta ${ }^{\circledR}$, HandiHaler ${ }^{\circledR}$ and Turbohaler ${ }^{\circledR}$ at a pressure drop of $4 \mathrm{kPa}$.

Flow profiles measured during Characterisation and Respiration measurements for different dry powder inhalers are presented in Figure 3. During Characterisation measurements, the resistance of the system is given mainly by the inner resistance of the used dry powder inhaler. The peak inspiratory flow, measured at the pressure drop of $4 \mathrm{kPa}$, ranges from 21 to $80 \mathrm{~L} / \mathrm{min}$. The shape of the inhalation profile, shown in Figure 3A is characteristic for each used dry powder inhaler and reflects the individual constructional solution of the included devices. Vibrations of the capsule, for example, are distinctive for HandiHaler® and manifest in rapid oscillations of the inspiratory flow. Inner resistance of the dry powder inhalers also influences the inhalation

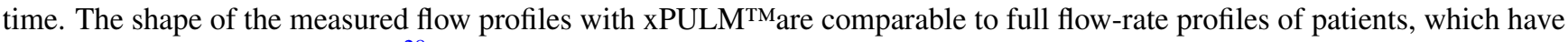
been compiled by Horváth et al. ${ }^{28}$ from various studies and their own measurements.

The inspiratory flow rate during Respiration measurements is, in contrast to Characterisation measurements, influenced by resistance and compliance of the included upper airway model and the primed porcine lung, respectively. This is evident for dry powder inhalers with low inner resistance (e.g., Breezhaler®) where the inspiratory flow rate drops by almost 50\%. The DPIs with high inner resistance (e.g., HadiHaler®) are influenced moderately as the increase of the overall system resistance is lower. The peak inspiratory flow, measured at the pressure drop of $4 \mathrm{kPa}$, ranges from 18 to $41 \mathrm{~L} / \mathrm{min}$.

The flow results of the different dry powder inhalers, as shown in Figure 3, allow conclusions on the handling of the inhaler and its characteristics during use. The HandiHaler® for example shows a wider range of flow values as well as higher volatility in pressure drop values (see Figure 4), than most of the other inhalers. This is mainly caused by the propelling mechanism, which is based on the mechanical movement of the aerosol loaded capsule. Based on the user guide the capsule has to move (also acoustically noticeable) within the inhaler, in order to disperse the powder. This oscillating movement leads to a volatile flow and therefore also oscillating pressure drop measurements. Therefore characterisation of this inhaler is influenced by the handling of the capsule and inhaler.

A comparable observation can be made for the use of the second capsule-based dry powder inhaler, the Breezhaler@. This product is also based on the oscillation of the capsule in order to propel the aerosol properly. These oscillations are moreover influenced by the holding position and angle of the device during inhalation. In contrast to the HandiHaler®, the capsule within the Breezhaler® is not limited in movement mechanically, but mainly by gravitation. When the Breezhaler® has moved to a horizontal position the likelihood of the capsule dropping out of the holding cavity increases and therefore influences the aerosol production mechanism. 
The effect on changed flow profiles caused by a different lung equivalent can be observed in Figure 3 . The compliance of the introduced lung tissue (depicted by the flow curves in part B of the same figure) influences the peak flow as well as the inhalation time and flow profile. The anatomic components of the used porcine lung and its geometric properties lead to a prolonged inhalation time and flattened flow profile when using identical inhalation settings like inhalation time $\left(\mathrm{t}_{\mathrm{INH}}\right)$ and aimed pressure drop $\left(\mathrm{P}_{\mathrm{DROP}}\right)$ as with the polymer breathing bags as lung equivalent.

\subsection{Influence of the upper airway model and the primed porcine lung}
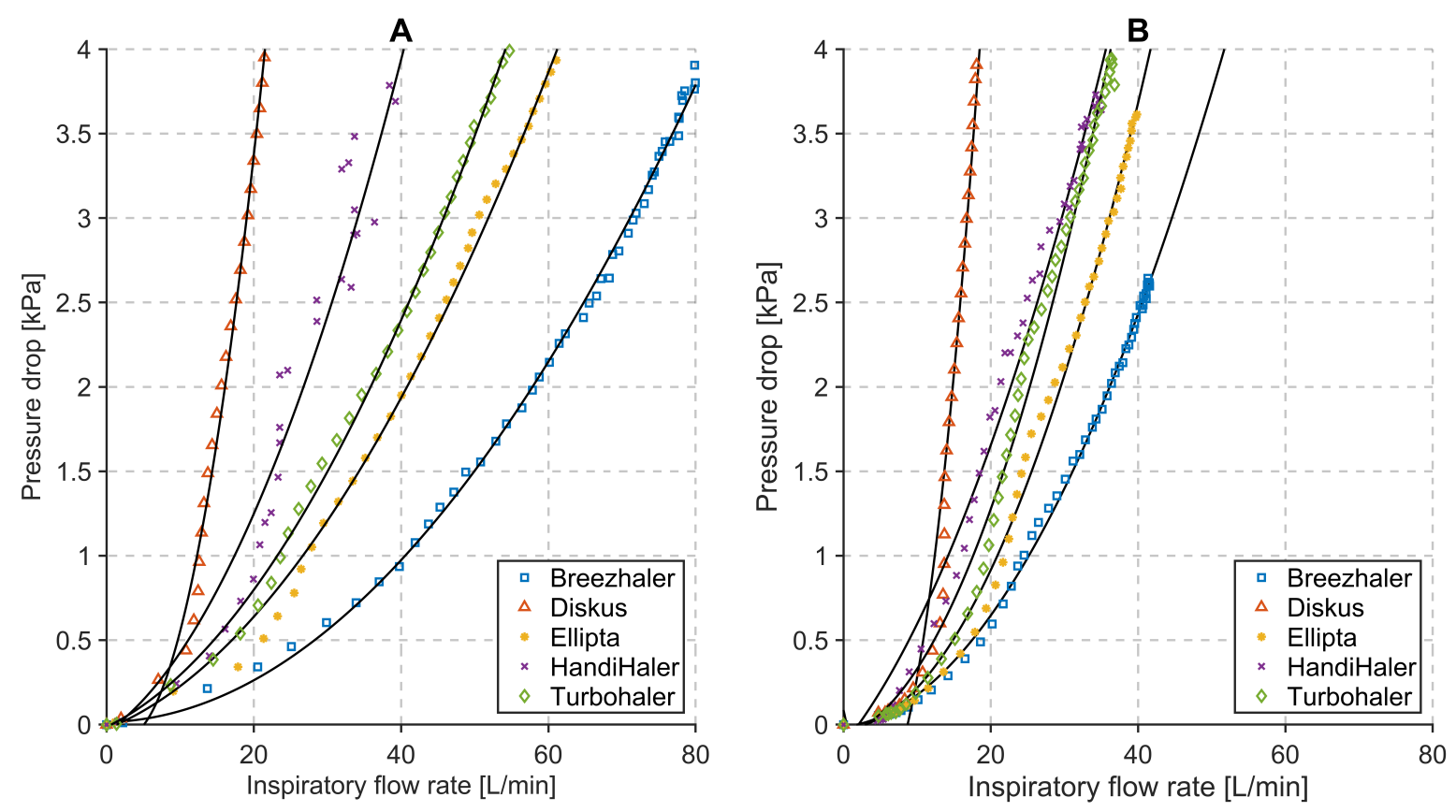

Figure 4. Relationships between inspiratory flow rate and pressure drop of five commercial dry powder inhalers during A) Characterisation measurements B) Respiration measurements.

Effects of the upper airway model and the primed porcine lung during Respiration measurements are evident from the relationship between inspiratory flow rate and pressure drop across the inhalers, see Figure 4B). The resistance of the measurement system increases significantly $(\mathrm{p}<0.01)$ with all inhalers (see Table 3 ) and the required pressure drop of $4 \mathrm{kPa}$ is reached for lower inspiratory flow rates.

The measurements revealed limitations in reaching the pressure drop of $4 \mathrm{kPa}$ consistently for Breezhaler®. Based on the recorded observations, the position of the capsule within the DPI, as well as the angle of the device are critical. Even a slight movement of the capsule changes the behaviour of the device. The pressure drop set prior to measurements could not be reached despite high inspiratory flow and prolonged inhalation time. According to Clark et. al ${ }^{7}$ a pressure drop $\leq 1 \mathrm{kPa}$ with any DPI is sufficient for the patient to receive an adequate lung dose. This criterion (defined as a minimum requirement) was met overall conducted measurements.

Relevant parameter values for the used DPIs, Characterisation measurements and Respiration measurements are summarised in Table 3. These parameter values complement the graphical result shown in Figure 3 and Figure 4. Additionally, they provide further inside about the relationship between the inner resistance of the dry powder inhalers, inhaled volume, inhalation time and peak inspiratory flow at particular pressure drop values.

The difference between the inner resistances of dry powder inhalers measured during characterisation and the values extracted from the literature is in an acceptable tolerance range of $\pm 0.005 \mathrm{kPa}^{1 / 2} / \mathrm{L} / \mathrm{min}$, with exception of Diskus@ (see Table 2 and Table 3 ). Results show, that the Diskus ${ }^{\circledR}$ inhaler, which was included in the measurement setup, exhibits high inner resistance of $0.0933 \mathrm{kPa}^{1 / 2} / \mathrm{L} / \mathrm{min}$. However, these results do not fully align with characterisation values provided by other groups. The calculated inner resistance of a Diskus@ inhaler has been published with $0.0254 \mathrm{kPa} 1 / 2 / \mathrm{L} / \mathrm{min}$, similar to the values for an Ellipta® DPI. This discrepancy can be explained by suboptimal storage conditions for this inhaler. 
Table 3. Summary of the relevant parameter values for the used DPIs, Characterisation measurements and Respiration measurements. Where: $\mathrm{V}_{\mathrm{INH}}$ - inhaled volume, $\mathrm{P}_{\mathrm{DROP}}$ - pressured drop across the inhaler during inhalation, PIF - peak inspiratory flow, and $\mathrm{t}_{\mathrm{INH}}$ - inhalation time.

\begin{tabular}{|c|c|c|c|c|c|c|c|c|c|c|}
\hline \multirow{2}{*}{$\begin{array}{l}\text { Dry powder inhalers } \\
\text { Device }\end{array}$} & \multicolumn{5}{|c|}{ Characterisation parameters } & \multicolumn{5}{|c|}{ Respiration parameters } \\
\hline & $\begin{array}{l}\text { Vinh } \\
{[\mathrm{L}]}\end{array}$ & $\begin{array}{l}\text { PDROP } \\
{[\mathrm{kPa}]}\end{array}$ & $\begin{array}{l}\mathrm{PIF} \\
{[\mathrm{L} / \mathrm{min}]}\end{array}$ & $\begin{array}{l}\text { tinh } \\
{[\mathrm{s}]}\end{array}$ & $\begin{array}{l}\text { Resistance } \\
{\left[\mathrm{kPa}^{1 / 2} / \mathrm{L} / \mathrm{min}\right]}\end{array}$ & $\begin{array}{l}\text { Vinh } \\
{[\mathrm{L}]}\end{array}$ & $\begin{array}{l}\text { PDROP } \\
{[\mathrm{kPa}]}\end{array}$ & $\begin{array}{l}\mathrm{PIF} \\
{[\mathrm{L} / \mathrm{min}]}\end{array}$ & $\begin{array}{l}\text { tinh } \\
{[\mathrm{s}]}\end{array}$ & $\begin{array}{l}\text { Resistance } \\
{\left[\mathrm{kPa}^{1 / 2} / \mathrm{L} / \mathrm{min}\right]}\end{array}$ \\
\hline Seebri® Breezhaler ${ }^{\circledR}$ & 4.73 & 3.94 & 80.57 & 3.00 & 0.0246 & 2.66 & 2.67 & 41.76 & 3.00 & $0.0392 *$ \\
\hline Seretide $®$ Diskus ${ }^{\circledR}$ & 2.01 & 4.10 & 21.70 & 1.20 & 0.0933 & 1.79 & 4.03 & 18.25 & 1.20 & $0.1101 *$ \\
\hline Anoro $®$ Ellipta $₫$ & 3.49 & 4.39 & 65.29 & 2.10 & 0.0321 & 2.58 & 3.62 & 40.03 & 2.10 & $0.0475^{*}$ \\
\hline Spiriva ${ }^{\circledR}$ HandiHaler ${ }^{\circledR}$ & 2.56 & 4.24 & 44.18 & 1.40 & 0.0466 & 2.59 & 3.77 & 35.32 & 1.40 & $0.0550^{*}$ \\
\hline Symbicort ${ }^{\circledR}$ Turbohaler ${ }^{\circledR}$ & 2.92 & 3.99 & 54.70 & 1.60 & 0.0365 & 2.41 & 3.96 & 36.80 & 1.60 & $0.0541 *$ \\
\hline
\end{tabular}

$* \mathrm{p}<0.01$ for difference between resistances measured with and without the upper airway model

\subsection{Changes in mean particle diameter}

Changes in mean particle diameter (M1) during DPI Characterisation and Respiration measurements using the upper airway model and primed porcine lung are depicted in Figure 5. During characterisation measurements the mean particle diameter ranges from $0.95 \mu \mathrm{m}$ (TurboHaler®) to $2.99 \mu \mathrm{m}$ (Diskus $\left.{ }^{\circledR}\right)$. These results are comparable to the findings of Horváth et al. ${ }^{28}$ who reported particles ranging from $2.20 \mu \mathrm{m}$ (Ellipta®) to $3.90 \mu \mathrm{m}$ (HandiHaler®). Differences in the absolute values of mean particle diameter are to be expected, based on the different components of the used measurement setup. As reported by several authors ${ }^{7,8,28,29}$ the aerodynamic properties of the generated drug particles vary based on quantities such as peak inspiratory flow rate, flow acceleration, inhalation time and inhaled volume. These quantities are patient-specific and vary from the presented measurements. Filtration properties of the upper airway model cause the mean particle diameter to shift towards lower values during inhalation. This can be observed for all tested DPI, as Figure 5A) \& B) depicts. It has been shown, that the upper respiratory tract indeed acts as a particulate filter. Larger particles $(>3 \mu \mathrm{m})$ deposit more easily in the upper respiratory tract. However, the smaller particles $(<3 \mu \mathrm{m})$ pass more easily into the lower respiratory tract as the filtration function decreases with particle size. ${ }^{30,31}$
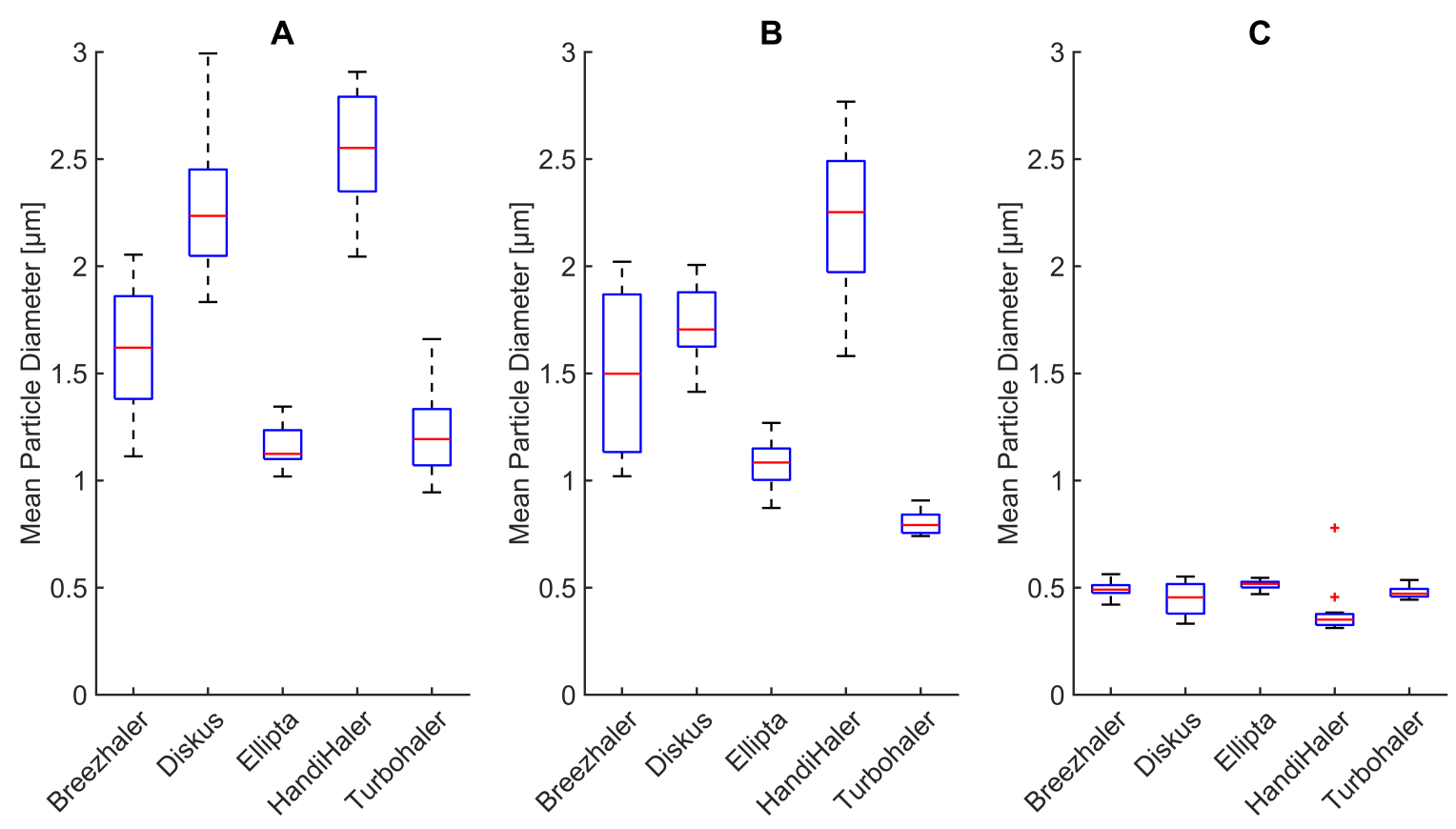

Figure 5. Changes in mean particle diameter during A) Characterisation measurements B) Inhalation measurements C) Exhalation measurements for five commercial dry powder inhalers 
Exhaled particles during our measurements are characterised by a mean particle diameter in a narrow range from $0.31 \mu \mathrm{m}$ (HandiHaler®) to $0.56 \mu \mathrm{m}$ (BreezHaler $\left.{ }^{\circledR}\right)$. These results were expected as the total deposition of aerosol particles in the lung reaches its minimum at $0.5 \mu \mathrm{m}^{32,33}$. Furthermore, there is a significant difference $(\mathrm{p}<0.05)$ in mean particle diameter between inhaled and exhaled particles Figure 5B) \& C) for all tested DPIs (K-W test, $\mathrm{H}=17.29, \mathrm{p}=0.00003)$. This change is caused by the interaction of the aerosol particles with the primed porcine lung tissue. The interaction is caused by a highly complex and constantly changing inner geometry of the lung tissue, which influences the mean particle diameter. Additionally, the high relative humidity within the lung tissue may lead to growth and therefore also to adhesion of particles during the passage.

\subsection{Total lung deposition}

The difference between the particle number concentration in inhaled and exhaled air can be considered as total lung deposition (TLD). The TLD expressed as a percentage of particle number concentration measured after the upper airway model for five commercial dry powder inhalers is depicted in Figure 6.

Differences between aerosol particle number concentration sampled from the air stream during A) Inhalation and B) Exhalation for all inhalers are depicted in Figure 7 . There is a statistically significant difference $(p<0.05)$ between particle number concentration in inhaled and exhaled airstream for all tested inhalers (K-W test, $\mathrm{H}=17.29, \mathrm{p}=0.00003$ ). This is caused by particles depositing in the primed porcine lung.

The chosen measurement setup causes the generated drug particles from the DPIs to be inhaled through the upper airway model. The upper airway model represents the naso-oro-pharyngo-laryngeal region (extrathoracic region). Here, bigger particles $(>3 \mu \mathrm{m})$ deposit mainly due to effects of inertial impaction ${ }^{33}$. The rest of the drug particles penetrates the deeper regions of the respiratory tract model and reach the primed porcine lung. The complex geometry and high relative humidity of the lung present an ideal environment for most of the particles to deposit due to sedimentation and Brownian diffusion ${ }^{20,33}$.

Regional lung deposition and bronchodilator response of pharmaceutical aerosols was studied in depth by Usmani et. al ${ }^{34}$. Their results confirm that the small particles are exhaled more with exhalation fractions for particle diameters $1.5 \mu \mathrm{m}, 3 \mu \mathrm{m}$ and $6 \mu \mathrm{m}$ being $22 \%, 8 \%$, and $2 \%$ respectively ${ }^{34}$. A lung deposition study conducted by Newman et. al ${ }^{35}$ in healthy human subjects showed a fraction of exhaled dose in exhaled air to be $1.2 \%$. In this study, however, a MaGhaler dry powder inhaler was used to aerosolised the powder.

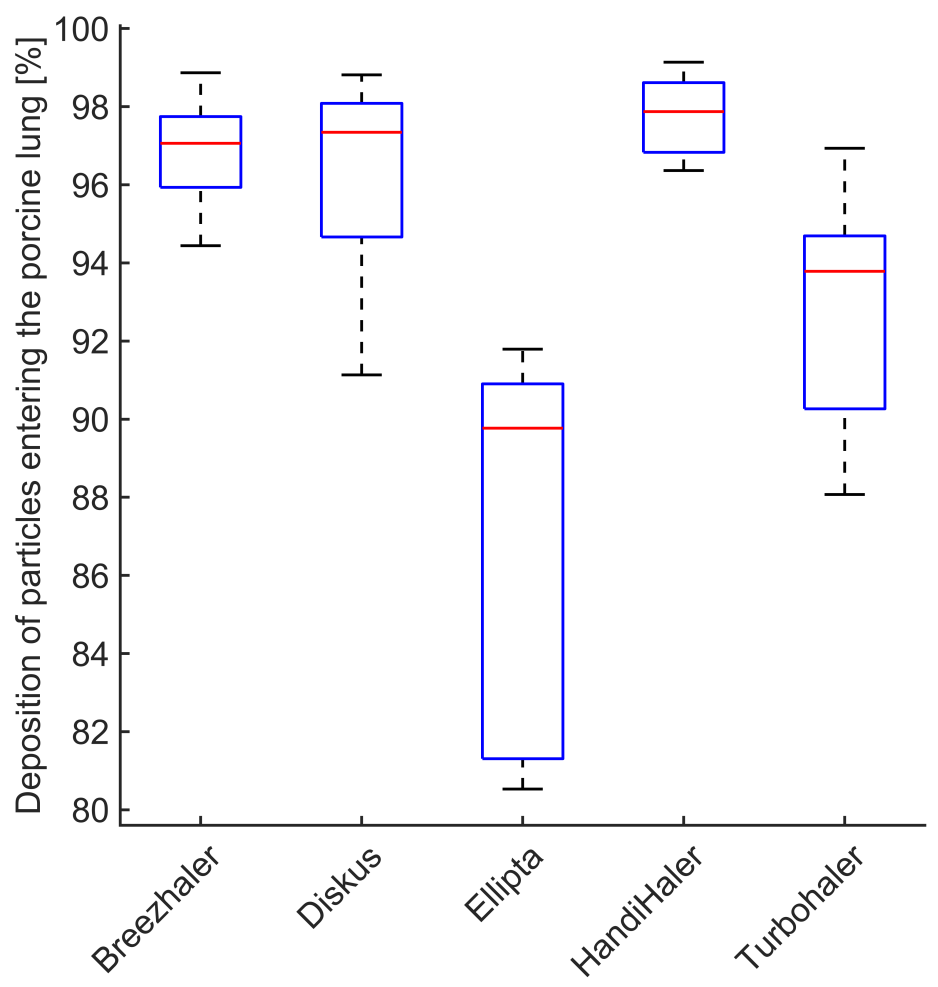

Figure 6. Deposition of aerosol particles in the porcine lung (expressed as a percentage of particle number concentration measured after the upper airway model) for five commercial dry powder inhalers. 
Virchow et al. ${ }^{36}$ investigated the deposition of dry powder-based fixed combination in healthy subjects, asthmatic patients, and COPD patients. They found no significant difference in drug deposition between the 3 groups. They reported that the amount exhaled ranged between $1.6 \%$ and $3.3 \%$. These findings are consistent with our measurements where the mean number concentrations exhaled are 2.94\% (BreezHaler®), 2.66\% (Diskus®), 10.24\% (Ellipta®) 2.13\% (HandiHaler®) and 6.22\% (Turbohaler®).
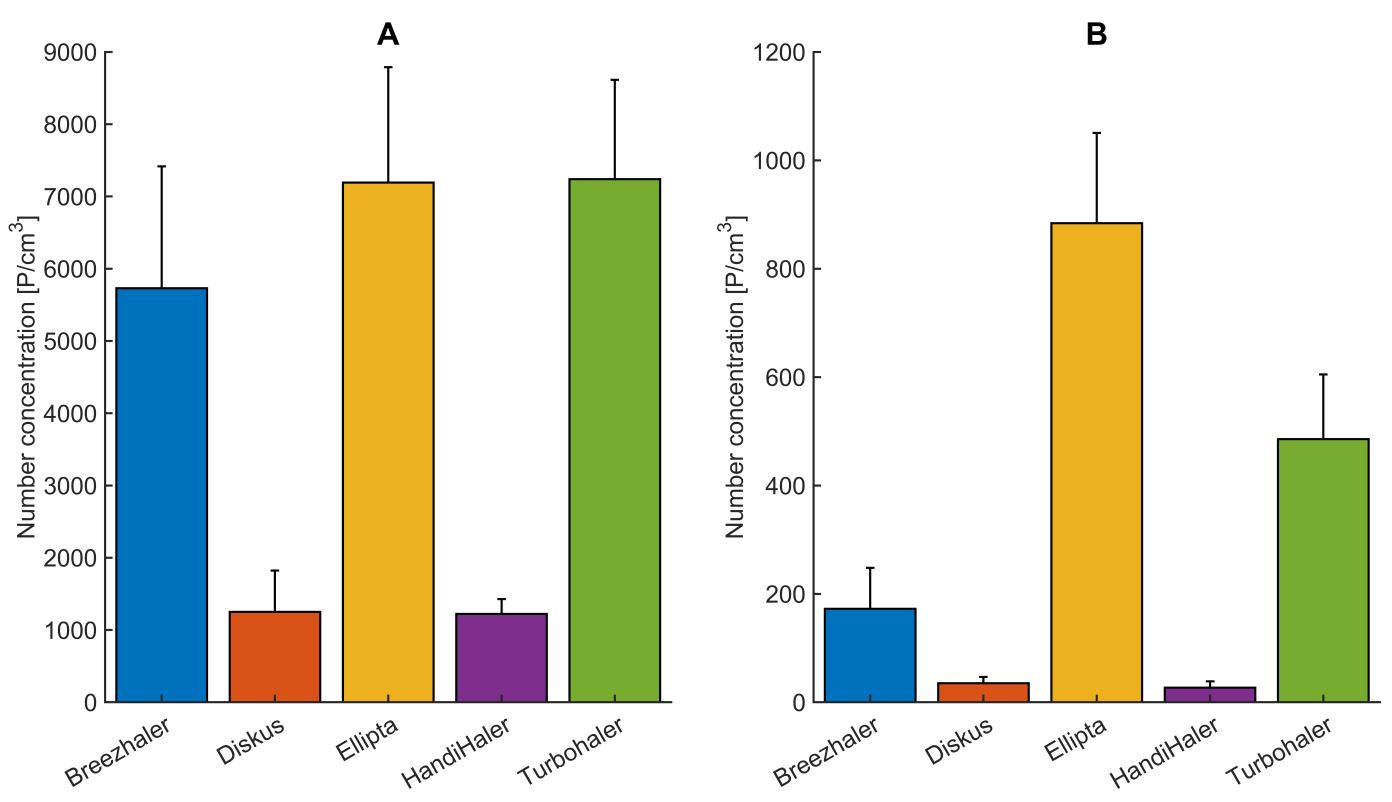

Figure 7. Differences between aerosol particle number concentration sampled from the air stream during A) Inhalation and B) Exhalation for five commercial dry powder inhalers.

\section{Summary and Conclusion}

For a large number of patients, DPI is the device of choice for the delivery of pharmaceuticals to manage asthma and chronic obstructive pulmonary disease ${ }^{8,37}$. The number of commercially available DPIs is growing ${ }^{7}$ with inhalers vary in their design, operating mechanisms, and resistance to inhaled airflow ${ }^{7,38}$. Accounting for these properties and the patient's ability to use the specific device is essential for efficient drug delivery. Testing setups provide an option to evaluated aerosolised dry powders generated by DPIs and allow for further insights about DPI performance under various conditions ${ }^{39-42}$.

In this work, aerosol particle diameter and particle number concentration of pharmaceutical aerosols generated by five commercially available DPIs were investigated. The measurement setup consists of the active respiratory system model xPULM ${ }^{\mathrm{TM}}$ in combination with optical aerosol spectrometry and upper airway model. This allows for the evaluation of pharmaceutical aerosols and the calculation of total lung deposition under realistic inhalation and exhalation simulations. Generally, experimental data measured during exhalation are scarce when in-vitro pharmaceutical aerosol test systems are employed.

To represent the human upper respiratory tract with high fidelity a mechanical upper airway model was developed, manufactured, and introduced as a part of the XPULM ${ }^{\mathrm{TM}}$. The model was derived from CT examinations of a 28-years-old healthy male. Additionally, the primed porcine lung was used to simulate the complexity of the human lower respiratory tract. The integration of the upper airway model and primed porcine into the XPULM ${ }^{\mathrm{TM}}$ model represents an important step forward towards the realistic simulation of a breathing human. Additionally, the combination of xPULM ${ }^{\mathrm{TM}}$ with an optical aerosol spectrometer presents an alternative approach suitable for applications in aerosol research.

Our results can be summarised as follows:

- Integration of an upper airway model, as a part of the XPULM ${ }^{\mathrm{TM}}$, increases the resistance of the overall system. This affects inhalatory flow and pressure characteristics of DPIs with lower inner resistance more than DPIs with high inner resistance, where the change is negligible.

- Inclusion of a porcine lung as a representation of the human lower respiratory tract (compliant with the 3R principles) allows comparable particle deposition to reported findings 
- Handling and placement of a capsule into single-dose DPI influences aerosol production during inhalation drug therapy. Slight changes in capsule placement may influence the amount of delivered drug. Correct handling of the inhaler should be emphasised alongside acceptable inhalation manoeuvres (as defined by the device manufacturer) to ensure the desired result.

- Mean particle diameter is reduced by the filtration properties of the mechanical upper airway model, effecting mostly bigger particles $(>3 \mu \mathrm{m})$. Such models, when based on CT examinations, are reliably representing the function of the human upper respiratory tract.

- Majority of particles entering the porcine lung deposits there. The minimum deposition is reached for particle size of $(0.5 \mu \mathrm{m})$. The primed porcine lung is therefore a suitable lung equivalent and represents the human lung well.

- Sampling of the airstream during inhalation and exhalation and its subsequent evaluation using optical aerosol spectrometry techniques is a viable alternative to evaluate particle diameter and particle number concentration.

In conclusion, the XPULM ${ }^{\mathrm{TM}}$ active respiratory system model in combination with the introduced upper airway model and the optical aerosol spectrometer is a viable option for investigating particle diameter and particle number concentration (total lung deposition) of pharmaceutical aerosol under realistic breathing conditions. The model can support the reduction of animal experimentation in aerosol research and provide an alternative to experiments with human subjects. Further research will focus on the inclusion of additional components and techniques (e.g., nano-dots, tissue sampling, histopathology) to quantify the regional deposition of pharmaceutical aerosols in a lung tissue obtained by $3 \mathrm{R}$ compliant processes.

\section{References}

1. Forum of International Respiratory Societies. The Global Impact of Respiratory Disease (European Respiratory Society, 2017).

2. Eurostat. Respiratory diseases statistics - Statistics Explained (2020). Available at https://ec.europa.eu/eurostat/ statistics-explained/index.php?title=Respiratory_diseases_statistics\&oldid=497079.

3. Sorino, C., Negri, S., Spanevello, A., Visca, D. \& Scichilone, N. Inhalation therapy devices for the treatment of obstructive lung diseases: the history of inhalers towards the ideal inhaler. Eur. J. Intern. Medicine 75, 15-18, DOI: 10.1016/J.EJIM.2020.02.023 (2020).

4. Wintemute, K. \& Miller, F. Dry powder inhalers are environmentally preferable to metered-dose inhalers. $C M A J \mathbf{1 9 2}$, E846-E846, DOI: 10.1503/CMAJ.75949 (2020).

5. Rau, J. L. Practical problems with aerosol therapy in COPD. Respir. Care 51, 158-172 (2006).

6. Geller, D. E. Comparing clinical features of the nebulizer, metered-dose inhaler, and dry powder inhaler. Respir. Care 50, 1313-1322 (2005). http://rc.rcjournal.com/content/50/10/1313.full.pdf.

7. Clark, A. R., Weers, J. G. \& Dhand, R. The Confusing World of Dry Powder Inhalers: It Is All about Inspiratory Pressures, Not Inspiratory Flow Rates. J. Aerosol Medicine Pulm. Drug Deliv. 33, 1-11, DOI: 10.1089/jamp.2019.1556 (2020).

8. Atkins, Smaldone, MacIntyre, Hickey \& Amato, M. T. Dry powder inhalers: An overview - Discussion. Respir. Care 50, 1312 (2005).

9. Mahler, D. A., Waterman, L. A. \& Gifford, A. H. Prevalence and COPD phenotype for a suboptimal peak inspiratory flow rate against the simulated resistance of the diskus® dry powder inhaler. J. Aerosol Medicine Pulm. Drug Deliv. 26, 174-179, DOI: 10.1089/jamp.2012.0987 (2013).

10. Grant, A. C., Walker, R., Hamilton, M. \& Garrill, K. The ELLIPTA® dry powder inhaler: Design, functionality, in vitro dosing performance and critical task compliance by patients and caregivers. J. Aerosol Medicine Pulm. Drug Deliv. 28, 474-485, DOI: 10.1089/jamp.2015.1223 (2015).

11. Mahler, D. A. Peak inspiratory flow rate as a criterion for dry powder inhaler use in chronic obstructive pulmonary disease. Annals Am. Thorac. Soc. 14, 1103-1107, DOI: 10.1513/AnnalsATS.201702-156PS (2017).

12. Duarte, A. G. et al. Spirometry measurement of peak inspiratory flow identifies suboptimal use of dry powder inhalers in ambulatory patients with COPD. Chronic Obstr. Pulm. Dis. 6, 246-255, DOI: 10.15326/jcopdf.6.3.2018.0163 (2019).

13. Chen, S. Y., Huang, C. K., Peng, H. C., Yu, C. J. \& Chien, J. Y. Inappropriate Peak Inspiratory Flow Rate with Dry Powder Inhaler in Chronic Obstructive Pulmonary Disease. Sci. Reports 10, 1-9, DOI: 10.1038/s41598-020-64235-6 (2020). 
14. Taki, M., Marriott, C., Zeng, X. M. \& Martin, G. P. Aerodynamic deposition of combination dry powder inhaler formulations in vitro: A comparison of three impactors. Int. J. Pharm. 388, 40-51, DOI: 10.1016/j.ijpharm.2009.12.031 (2010).

15. Versteeg, H. K. et al. A cross-industry assessment of the flow rate-elapsed time profiles of test equipment typically used for dry-powder inhaler (DPI) testing: Part 2- analysis of transient air flow in the testing of DPIs with compendial cascade impactors. Aerosol Sci. Technol. 54, 1448-1470, DOI: 10.1080/02786826.2020.1792825 (2020).

16. Greguletz, R. et al. A cross-industry assessment of the flow rate-time profiles of test equipment typically used for dry-powder inhaler (DPI) testing: Part 1-compendial apparatuses. Aerosol Sci. Technol. 54, 1424-1447, DOI: 10.1080/ 02786826.2020 .1792824 (2020).

17. Wei, X. et al. In vitro tests for aerosol deposition. VI: Realistic testing with different mouth-throat models and in vitro - In vivo correlations for a dry powder inhaler, metered dose inhaler, and soft mist inhaler. J. Aerosol Medicine Pulm. Drug Deliv. 31, 358-371, DOI: 10.1089/jamp.2018.1454 (2018).

18. Ravi Kannan, R. et al. Pharmaceutical aerosols deposition patterns from a Dry Powder Inhaler: Euler Lagrangian prediction and validation. Med. Eng. Phys. 42, 35-47, DOI: 10.1016/j.medengphy.2016.11.007 (2017).

19. Kopsch, T., Murnane, D. \& Symons, D. Computational modelling and experimental validation of drug entrainment in a dry powder inhaler. Int. J. Pharm. 553, 37-46, DOI: 10.1016/j.ijpharm.2018.10.021 (2018).

20. Chalvatzaki, E., Chatoutsidou, S. E. \& Lazaridis, M. Simulations of the deposition of pharmaceutical aerosols in the human respiratory tract by dry powder inhalers (DPIs). J. Drug Deliv. Sci. Technol. 59, 101915, DOI: 10.1016/J.JDDST. 2020.101915 (2020).

21. Finlayson-Pitts, B. J. \& Pitts, J. N. Analytical Methods and Typical Atmospheric Concentrations for Gases and Particles. Chem. Up. Low. Atmosphere 547-656, DOI: 10.1016/B978-012257060-5/50013-7 (2000).

22. Kulkarni, V. Handbook of non-invasive drug delivery systems : science and technology (2009).

23. Darquenne, C. Deposition mechanisms. J. Aerosol Medicine Pulm. Drug Deliv. 33, 181-185, DOI: 10.1089/jamp.2020. 29029.cd (2020).

24. Tsuda, A., Henry, F. S. \& Butler, J. P. Particle transport and deposition: Basic physics of particle kinetics. Compr. Physiol. 1437-1471, DOI: 10.1002/cphy.c100085 (2013).

25. Chow, A. H. L., Tong, H. H. Y., Chattopadhyay, P. \& Shekunov, B. Y. Particle engineering for pulmonary drug delivery. Pharm. Res. 24, 411-437, DOI: 10.1007/s11095-006-9174-3 (2007).

26. Pasteka, R., Forjan, M., Sauermann, S. \& Drauschke, A. Electro-mechanical Lung Simulator Using Polymer and Organic Human Lung Equivalents for Realistic Breathing Simulation. Sci. Reports 9, 19778 (2019).

27. Russell, W. M. S. \& Burch, R. L. The principles of humane experimental technique (Methuen London, 1959).

28. Horváth, A., Balásházy, I., Tomisa, G. \& Farkas, Á. Significance of breath-hold time in dry powder aerosol drug therapy of COPD patients. Eur. J. Pharm. Sci. 104, 145-149, DOI: 10.1016/j.ejps.2017.03.047 (2017).

29. Buttini, F. et al. Effect of Flow Rate on In Vitro Aerodynamic Performance of NEXThaler® in Comparison with Diskus ${ }^{\circledR}$ and Turbohaler® Dry Powder Inhalers. J. Aerosol Medicine Pulm. Drug Deliv. 29, 167-178, DOI: 10.1089/jamp.2015.1220 (2016).

30. Sahin-Yilmaz, A. \& Naclerio, R. M. Anatomy and physiology of the upper airway. Proc. Am. Thorac. Soc. 8, 31-39, DOI: 10.1513/pats.201007-050RN (2011).

31. Thomas, R. J. Particle size and pathogenicity in the respiratory tract. Virulence 4, 847-858, DOI: 10.4161/viru.27172 (2013).

32. Lippmann, M., Yeates, D. B. \& Albert, R. E. Deposition, retention, and clearance of inhaled particles. Br. J. Ind. Medicine 37, 337-362, DOI: 10.1136/oem.37.4.337 (1980).

33. Darquenne, C. Aerosol deposition in health and disease. J. Aerosol Medicine Pulm. Drug Deliv. 25, 140-147, DOI: 10.1089/jamp.2011.0916 (2012).

34. Usmani, O. S., Biddiscombe, M. F. \& Barnes, P. J. Regional lung deposition and bronchodilator response as a function of B2-agonist particle size. Am. J. Respir. Critical Care Medicine 172, 1497-1504, DOI: 10.1164/rccm.200410-1414OC (2005).

35. Newman, S. et al. Lung deposition of salbutamol in healthy human subjects from the MAGhaler dry powder inhaler. Respir. Medicine 96, 1026-1032, DOI: 10.1053/rmed.2002.1387 (2002). 
36. Virchow, J. C. et al. Lung Deposition of the Dry Powder Fixed Combination Beclometasone Dipropionate Plus Formoterol Fumarate Using NEXThaler® Device in Healthy Subjects, Asthmatic Patients, and COPD Patients. J. Aerosol Medicine Pulm. Drug Deliv. 31, 269-280, DOI: 10.1089/jamp.2016.1359 (2018).

37. Levy, M. L. et al. Understanding Dry Powder Inhalers: Key Technical and Patient Preference Attributes. Adv. Ther. 36, 2547-2557, DOI: 10.1007/s12325-019-01066-6 (2019).

38. Newman, S. P. \& Busse, W. W. Review: Evolution of dry powder inhaler design, formulation, and performance. Respir. Medicine DOI: 10.1053/rmed.2001.1276 (2002).

39. Abadelah, M., Abdalla, G., Chrystyn, H. \& Larhrib, H. Gaining an insight into the importance of each inhalation manoeuvre parameter using altered patients' inhalation profiles. J. Drug Deliv. Sci. Technol. 61, 102181, DOI: 10.1016/j.jddst.2020. 102181 (2021).

40. Hira, D., Okuda, T., Mizutani, A., Tomida, N. \& Okamoto, H. In Vitro Evaluation of Optimal Inhalation Flow Patterns for Commercial Dry Powder Inhalers and Pressurized Metered Dose Inhalers With Human Inhalation Flow Pattern Simulator. J. Pharm. Sci. 107, 1731-1735, DOI: 10.1016/j.xphs.2018.02.002 (2018).

41. Wei, X. et al. In vitro tests for aerosol deposition. VI: Realistic testing with different mouth-throat models and in vitro - In vivo correlations for a dry powder inhaler, metered dose inhaler, and soft mist inhaler. J. Aerosol Medicine Pulm. Drug Deliv. 31, 358-371, DOI: 10.1089/jamp.2018.1454 (2018).

42. Hamilton, M. et al. In vitro dosing performance of the ELLIPTA ${ }^{\circ}$ dry powder inhaler using asthma and COPD patient inhalation profiles replicated with the electronic lung (eLung ${ }^{\mathrm{TM}}$ ). J. Aerosol Medicine Pulm. Drug Deliv. 28, 498-506, DOI: 10.1089/jamp.2015.1225 (2015).

\section{Acknowledgements}

The authors would like to thank F. Enghuber, M. Malaskova, L. Schoellbauer for their valuable contributions during the creation of this manuscript.

\section{Author contributions statement}

Richard Pasteka: Conceptualization, Methodology, Validation, Data curation, Writing- Original draft preparation, Visualization, Investigation Pedro Santo da Costa: Formal analysis, Writing- Reviewing Mathias Forjan: Conceptualization, Investigation, Writing- Reviewing and Editing, Supervision.

\section{Declaration of Competing Interest}

The authors declare that they have no known competing financial interests or personal relationships that could have appeared to influence the work reported in this paper. 